\title{
Assessment of Factors Influencing the Patients' Level of Satisfaction from Health Care Services Provided in the Outpatient Department of a Tertiary Care Hospital: A Cross-Sectional Study
}

\author{
Suman Anand ${ }^{1}$, Vaibhav Jain ${ }^{2 *}$ and Akshai Kannan ${ }^{3}$ \\ ${ }^{1}$ Dental Officer, BDS, PGDHM, INDC Danteshwari, Mumbai, Maharashtra, India \\ ${ }^{2}$ Graded Specialist Prosthodontics, INDC Danteshwari, Mumbai, Maharashtra, India \\ ${ }^{3}$ Graded Specialist Orthodontics, INDC Danteshwari, Mumbai, Maharashtra, India \\ *Corresponding Author: Vaibhav Jain, Graded Specialist Prosthodontics, INDC \\ Danteshwari, Mumbai, Maharashtra, India.
}

Received: September 27, 2021

Published: October 12, 2021

(C) All rights are reserved by Suman Anand., et al.

\section{Abstract}

Aim: To determine the perceived levels of patient satisfaction with the Health Care Services provided in the Out-Patient Department, areas of dissatisfaction and to improve patient satisfaction levels by making recommendations to address the concerns of the patients in a tertiary care health center.

Materials and Methods: This study was a Descriptive Cross-Sectional Hospital based study. This study applied a quantitative approach to gather data to help determine factors influencing patients' satisfaction with Out Patient Department (OPD) services of hospital. The design elicited responses on dependent variable (patients' satisfaction) and the independent variables at the same time.

Results: The data was collected from December 2020 to February 2021 on all OPD Days. From amongst the 300 patients enrolled, 248 patients returned the filled Questionnaire, the Response Rate being 83\%. A large number of respondents approximating $91.0 \%$ $(n=224)$ were satisfied with the medical advice provided by the healthcare provider. In terms of Infrastructure related factors, the OPD waiting area was rated as comfortable by over $80 \%$ of the respondents who found the area satisfactory with adequate air circulation. Similar ratings were given for the seating arrangements in the OPD with around 78.5\% $(n=195)$ of the respondents satisfied and $15 \%(n=38)$ not satisfied with the arrangement.

Conclusion: The present study has provided valuable insight regarding patient satisfaction with outpatient health care services, and the predictors thereof. It may be useful in the future to investigate the satisfaction levels of other categories of patients such as inpatients and patients in specific super specialty OPDs, for comparative and sphere based remedial purposes.

Keywords: Patient Satisfaction; OPD Waiting Area; OPD Reception OPD Registration

\section{Introduction}

Patient satisfaction survey is one of the important tools for measuring the quality of management. Patient satisfaction or dissatisfaction is a complicated phenomenon that is linked to patient expectations, health status, personal characteristics, as well as health system characteristics. Outpatient Department (OPD) is the first point of contact of the hospital with patients and work as the shop window to whatever health maintenance service provided to the patients. There are various problems faced by the patients in outpatient department like overcrowding, delay in consultation, lack of proper guidance etc. that leads to patient dissatisfaction [1].

Citation: Suman Anand., et al. “Assessment of Factors Influencing the Patients' Level of Satisfaction from Health Care Services Provided in the Outpatient Department of a Tertiary Care Hospital: A Cross-Sectional Study". Acta Scientific Dental Sciences 5.11 (2021): 02-10. 
To overcome this type of problem survey is one the best method to find out how far patients are satisfied with the service and what action could be taken to avoid dissatisfaction of the patient. Patient Satisfaction is indeed a complex and multifactorial concept and therefore there is no universally acceptable definition of Patient Satisfaction. The World Health Organisation defines Patient Satisfaction as the interlinking relationship between perceived needs, patient expectations and experiences [2].

Patient satisfaction is as important as other clinical health measures and is a primary means of measuring the effectiveness of health care delivery. The current competitive environment has forced health care organizations to focus on patient satisfaction as a way to gain and maintain market value [3]. Patient satisfaction surveys can be tools for learning, they can give proportion to problem areas and a reference point for making management decisions. Long waiting time, inadequate information, poor attitude of staff, poor communication, general environment and conditions of facilities etc. are some of the common sources of patient's dissatisfaction. For these reasons, this study will determine the perceived levels of patient satisfaction, factors influencing the satisfaction and areas of dissatisfaction with the Health Care Services provided in the Out-Patient Department of a Tertiary Care Hospital.

\section{Materials and Methods}

The main objective of this research was to assess the level of patient satisfaction with Outpatient Department's services regarding Physician-Patient interaction, Nurse-Patient interaction, and $\mathrm{Pa}-$ tient's Satisfaction in term of Convenience, Courtesy, and Quality of Care at Tertiary Care Hospital. This study was a Descriptive CrossSectional Hospital based study. This study applied a quantitative approach to gather data to help determine factors influencing patients' satisfaction with Out Patient Department (OPD) services of the Hospital. The design elicited responses on dependent variable (patients' satisfaction) and the independent variables at the same time.

Study was carried out at Tertiary Care Hospital after obtaining necessary clearances from the Institution's Ethics Committee. The study was carried out between December 2020 to February 2021 on patients visiting the Hospital, OPD services and fulfilling the Inclusion and Exclusion criteria.

\section{Study population}

Targeted samples were randomly drawn daily from the patients who visited the OPD during the period of data collection. Around 250 patients willing for the study and fulfilling the inclusion criteria were included in the study and administered the Questionnaire during their visit to OPD.

\section{Inclusion criteria}

- $\quad$ Adult patients of either sex - age group of 18 to 85 years.

- Willing to participate.

- Ability to sign informed consent.

- Patients who had made at least two visits to the hospital in the last one year.

\section{Exclusion criteria}

- Patients in serious condition requiring urgent attention.

- Patients with mental health conditions.

- $\quad$ Patients with speech or hearing disabilities.

\section{Ethical consideration}

The necessary permissions and clearances were obtained from the administrative authorities and the Institution's Ethics Committee. Patients were pre-informed regarding the study and adequately advised that their participation was voluntary and they could leave the study at any stage without any implications on their treatment and clinical management.

\section{Data collection instruments}

The variables measured in the study were categorized into Dependent and Independent variables.

\section{Dependent variables}

The dependent variable measured in this research was Patients' Satisfaction, which was ascertained by asking patients their expectations and perceptions on specific factors. These were based on the Seroquel model and included questions to elicit responses on variables such as Tangibles, Reliability, Responsiveness, Assurance, and Empathy.

\section{Independent variables}

The Independent Variables studied were the Socio-Demographic Profile related factors of the patients such as Age, Gender, Marital Status and Educational Qualifications etc. 


\section{Questionnaire (Appx A)}

A self-administered Questionnaire was chosen to gather the above data for this study. The Questionnaire was compiled based on information from other published articles after a thorough review of the literature. The instrument consisted of both closed and openended questions. The questions were framed in English; however basic and simple language was used in the framing of questions so as to enable ease of understanding by the participants. The 5-Point Likert Scale was used to determine the participants' level of agreement/disagreement with the set of statements which ranged from 'Strongly agree' on one end to 'Strongly disagree' on the other. The patients were asked to mark their level of satisfaction on the five points rating scale as follows:

1. Completely satisfied,

2. Some what satisfied,

3. Neutral,

4. Some what dissatisfied,

5. Completely dissatisfied.

\section{Data analysis}

Statistical analysis was performed after completion of the survey for the last patient included in the study. All the collected data was entered into Microsoft Excel worksheet and compiled as binomial dataset, then analysed using proportion test and deriving levels of significance. Descriptive statistics included computation of percentages, means and standard deviations. Further analysis was done using Regression Models and Analysis of Variance (ANOVA). The $\mathrm{p}$ value of less than $5 \%(\mathrm{p}<0.05)$ was considered as statistically significant in the analysis.

\section{Results}

The data was collected from December 2020 to February 2021 on all OPD Days. From amongst the 300 patients enrolled, 248 patients returned the filled Questionnaire, the Response Rate being 83\%. The eligible respondents were asked about the basic information of socio-demographic characteristics, experiences in OPD services, environmental factors and about the satisfaction of patients with services provided by the Healthcare facility. The responses were tabulated and analysed and the results are described hereinafter using tables, bar graphs, and pie charts. The Demographic
Data of the respondents is depicted in table 1 . The majority of the respondents were female (75.4\%), with an approximate female to male preponderance of 3:1. The maximum number of Male respondents were in the 30 - 40 years age group (37.5\%) while majority of females (81.0\%) were in the 20 - 30-year-old category. The demographic statistics are compared in figure 1 and marital status in figure 2. The age distribution and education profile depicted in table 1 and 2 respectively. The ordinal scoring pattern of the various sections of the questionnaire were tabulated and analysed. Statements relating to personality and interpersonal skills were rated highly among the patients.

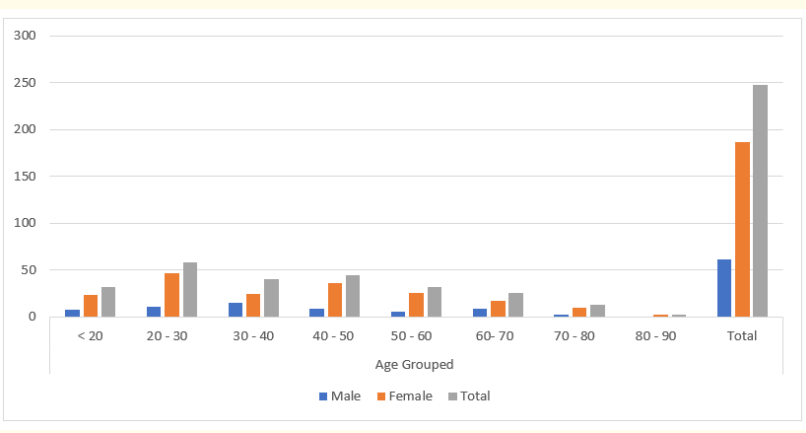

Figure 1: Age and sex distribution.

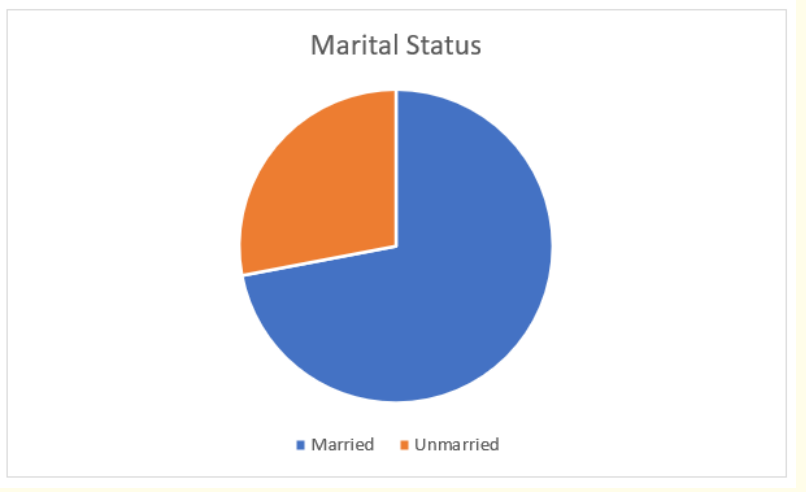

Figure 2: Marital status. 


\begin{tabular}{|l|c|c|c|}
\hline Age Grouped (in years) & Male & Female & Total \\
\hline$<20$ & 8 & 24 & 32 \\
\hline $20-30$ & 11 & 47 & 58 \\
\hline $30-40$ & 15 & 25 & 40 \\
\hline $40-50$ & 9 & 36 & 45 \\
\hline $50-60$ & 6 & 26 & 32 \\
\hline $60-70$ & 9 & 17 & 26 \\
\hline $70-80$ & 3 & 10 & 13 \\
\hline $80-90$ & 0 & 2 & 2 \\
\hline Total & 61 & 187 & 248 \\
\hline
\end{tabular}

Table 1: Demographic description.

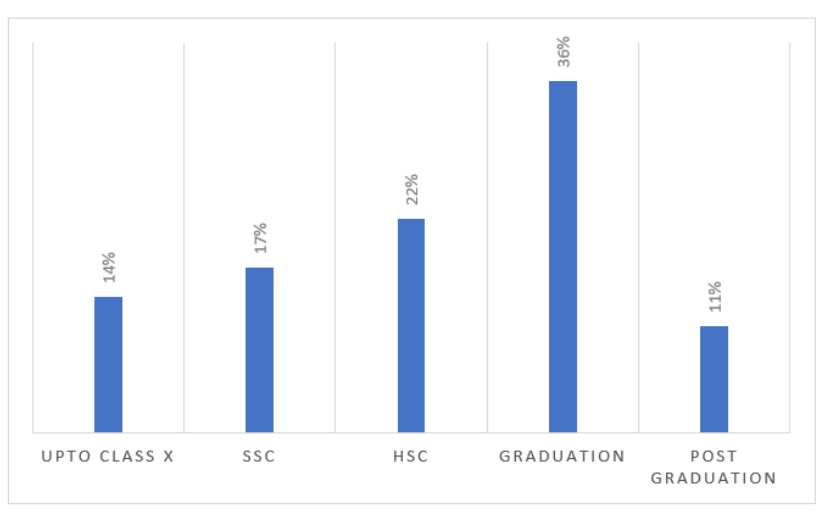

Table 2: Education profile.

A large number of respondents approximating 91.0\% $(n=224)$ were satisfied with the medical advice provided by the healthcare provider. The waiting time in the OPD was, however, a major point of dissatisfaction among a fairly high percentage of patients $(\mathrm{n}=$ $178 ; 71.8 \%)$. Around $64 \%(n=158)$ of the patients were satisfied with the duration of consultation with the treating doctor while $16.9 \%(n=42)$ were completely dissatisfied with the consultation time offered, the remaining being neutral. The detailed pattern of responses of Patient Satisfaction based on Interpersonal skills and OPD waiting period is illustrated in figure 3. In terms of Infrastructure related factors, the OPD waiting area was rated as comfortable by over $80 \%$ of the respondents who found the area satisfactory with adequate air circulation. Similar ratings were given for the seating arrangements in the OPD with around 78.5\% $(n=195)$ of the respondents satisfied and 15\% ( $n=38)$ not satisfied with the arrangement.
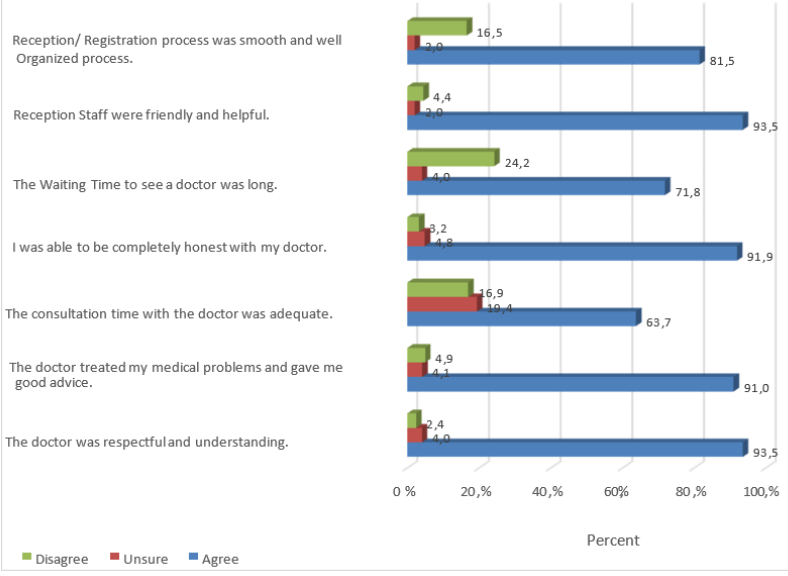

Figure 3: Patient satisfaction ratings: Interpersonal skills and waiting time.

In so far as the cleanliness of the hospital was concerned, $78.9 \%$ $(n=195)$ of the respondents were of the opinion that the institution was neat and tidy, whilst $16.6 \%(n=41)$ were not satisfied with the cleanliness of the hospital surroundings. On the other hand, most of the respondents were not satisfied with the overall condition and cleanliness of the toilets. While around $60 \%$ of respondents found the toilets location and ease of finding satisfactory, more than half the respondents $(54.0 \% ; n=134)$ were displeased with the condition of the toilets. Availability of clean drinking water was also a major determinant in patient satisfaction scale. Almost 30\% ( $n=75$ ) of respondents were not satisfied with the availability of drinking water facility and stated non availability of suitable drinking water in the OPD department, whilst less than half (49.6\%) were satisfied with the available drinking water in the OPD. The Infrastructural factors-based details of patient satisfaction are amply depicted in figure 4 . Over $90 \%(n=224)$ of the respondents visiting our Healthcare setup were pleased with the infrastructure facilities and treatment received at the centre. Only around 6\% of the respondents were unhappy with the infrastructure facilities 
and treatment received. Likewise, almost $88 \%(n=218)$ of the patients acknowledged that they were satisfied with the services and care received at this healthcare facility and that their overall experience was positive and surpassed expectations with only $3.6 \%$ of respondents disagreeing. Further augmenting this datum was the fact that almost $90 \%(n=222)$ of the respondents affirmed that not only would they visit our healthcare facility again if need arises but would also definitely recommend this hospital to other acquaintances. Only around 3\% (n= 8) were disappointed to the extent that they were unwilling to return or recommend this hospital whilst around 7\% $(n=18)$ were non-committal. The findings are depicted in figure 5. The data was further analysed to assess any relationships between the variables. The analysis revealed a statistically significant inverse relationship between education status and patient satisfaction with the level of care received at the hospital ( $p$ $<0.05)$. Patients who had basic primary schooling were more satisfied than patients who received secondary and tertiary education. There was no statistically significant association on analysis of the other demographic characteristics like age and gender.

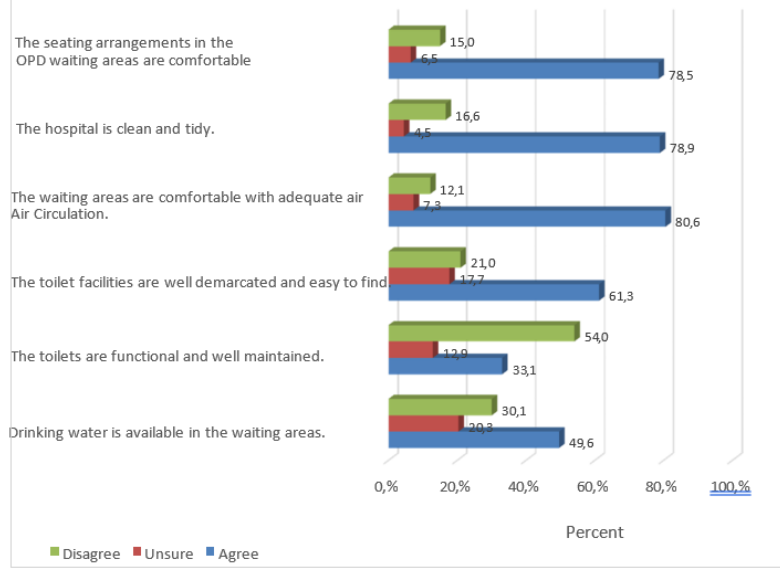

Figure 4: Patient satisfaction ratings: Infrastructure.

\section{Discussion}

Patient Satisfaction has long been used as a tool for assessing quality of care both at the level of individual health professional and for health care programs. Factors associated with patient's satisfaction are not fully understood. Patient satisfaction is deter-

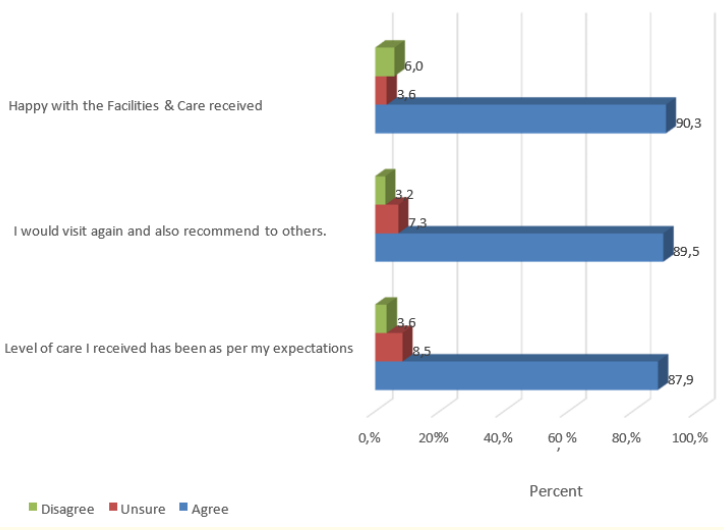

Figure 5: Overall patient satisfaction ratings.

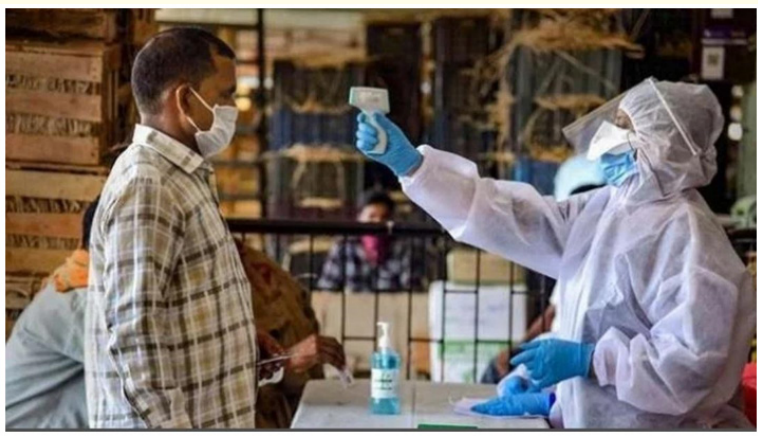

Figure 6: On reception screening services.

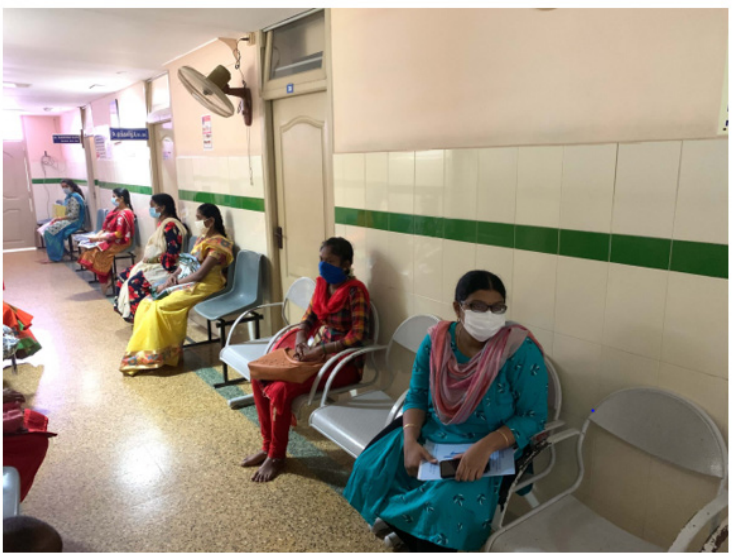

Figure 7: Photo of few patients waiting in the OPD. 
Assessment of Factors Influencing the Patients' Level of Satisfaction from Health Care Services Provided in the Outpatient Department of a Tertiary Care Hospital: A Cross-Sectional Study

\begin{tabular}{|c|c|c|c|}
\hline Question & & Response & N (\%) \\
\hline \multirow{3}{*}{1.} & \multirow{3}{*}{$\begin{array}{l}\text { Are You Afraid of Getting Infected with COVID-19 from a Patient and } \\
\text { Co-Worker? }\end{array}$} & Yes & $338(73.63 \%)$ \\
\hline & & No & $34(7.40 \%)$ \\
\hline & & Maybe & $87(19.0 \%)$ \\
\hline \multirow{3}{*}{2.} & \multirow{3}{*}{$\begin{array}{l}\text { Are You Anxious When Providing Treatment to a Patient who is } \\
\text { Coughing or Suspected of being Infected with COVID-19? }\end{array}$} & Yes & \multirow{2}{*}{$\begin{array}{c}393(85.62 \%) \\
32(7.0 \%)\end{array}$} \\
\hline & & No & \\
\hline & & Maybe & $34(7.40 \%)$ \\
\hline & \multirow{3}{*}{$\begin{array}{l}\text { Do You want to Close Your Dental Practice until the Number of CO- } \\
\text { VID-19 Cases Starts Declining? }\end{array}$} & Yes & $305(66.45 \%)$ \\
\hline & & No & $49(10.7 \%)$ \\
\hline & & Maybe & $105(23.0 \%)$ \\
\hline \multirow{3}{*}{4.} & \multirow{3}{*}{ Do You Feel Nervous when Talking to Patients in Close Vicinity? } & Yes & $268(58.39 \%)$ \\
\hline & & No & $129(28.10 \%)$ \\
\hline & & Maybe & $62(13.50 \%)$ \\
\hline & \multirow{3}{*}{$\begin{array}{l}\text { Do You have Fear that You Could Carry the Infection from Your Dental } \\
\text { Practice back to Your Family? }\end{array}$} & Yes & \multirow{2}{*}{$\begin{array}{l}426(92.9 \%) \\
13(2.83 \%)\end{array}$} \\
\hline & & No & \\
\hline & & Maybe & $20(4.35 \%)$ \\
\hline \multirow{3}{*}{6.} & \multirow{3}{*}{ Are You Afraid of Getting Quarantined if get Infected? } & Yes & $196(42.70 \%)$ \\
\hline & & No & $213(46.40 \%)$ \\
\hline & & Maybe & $50(10.9 \%)$ \\
\hline & \multirow{3}{*}{ Are You Anxious about the Cost of Treatment if You Get Infected? } & Yes & \multirow{2}{*}{$\begin{array}{c}155(33.8 \%) \\
216(47.06 \%)\end{array}$} \\
\hline & & No & \\
\hline & & Maybe & $88(19.17 \%)$ \\
\hline & \multirow{3}{*}{$\begin{array}{l}\text { Do You feel Afraid when you Hear that People are Dying Because of } \\
\text { COVID-19 }\end{array}$} & Yes & $327(71.24 \%)$ \\
\hline & & No & $50(10.9 \%)$ \\
\hline & & Maybe & $82(17.7 \%)$ \\
\hline
\end{tabular}

Table 3: Attitude and fear of Covid-19 among dental care professionals.

mined by several factors including treatment compliance, loyalty to a service provider, reduced medico-legal risk, age, education status, expectations, Interpersonal communication, health outcome, and patient's emotional and mental state [4].
Of the 248 respondents enrolled in our study around 75\% were female patients. Various studies on this subject have the reported similar findings which suggest that female patients make more use of health care facilities compared to males. Galhotra., et al. (2013) 


\begin{tabular}{|c|c|c|c|c|}
\hline \multicolumn{2}{|l|}{ Variable } & N (\%) & Mean (SD) & p-value \\
\hline \multicolumn{2}{|l|}{ Total } & 459 & $17.08(7.8)$ & \\
\hline Gender & $\begin{array}{c}\text { Male } \\
\text { Female }\end{array}$ & $\begin{array}{l}234(51.0 \%) \\
225(49.02 \%)\end{array}$ & $\begin{array}{l}15.71(7.4) \\
18.52(7.9)\end{array}$ & $<0.005^{*}$ \\
\hline \multirow{4}{*}{ Age } & $21-30$ & $176(38.34 \%)$ & $20.66(7.5)$ & \multirow{4}{*}{$<0.005^{*}$} \\
\hline & $31-40$ & $224(48.80 \%)$ & $14.64(7.1)$ & \\
\hline & $41-50$ & $53(11.55 \%)$ & $15.85(7.1)$ & \\
\hline & $>50$ & $06(1.30 \%)$ & $14.00(7.0)$ & \\
\hline \multirow{2}{*}{$\begin{array}{l}\text { Designa- } \\
\text { tion }\end{array}$} & Specialists & $251(54.7 \%)$ & $16.7(8.3)$ & \multirow[b]{2}{*}{0.23} \\
\hline & $\begin{array}{c}\text { General dental } \\
\text { practitioners }\end{array}$ & $208(45.31 \%)$ & $17.56(7.0)$ & \\
\hline \multirow{3}{*}{$\begin{array}{l}\text { Nature of } \\
\text { hospital }\end{array}$} & GOVT. hospital & $276(60.13 \%)$ & $16.60(7.8)$ & \multirow{3}{*}{0.40} \\
\hline & Private hospital & $38(8.3 \%)$ & $20.74(7.6)$ & \\
\hline & Private Clinic & $145(31.6 \%)$ & $17.04(7.6)$ & \\
\hline
\end{tabular}

Table 4: Comparison of PSS scores and socio-demographic characteristics among study participants.

The total PSS scores in the study sample ranged from $0-38$, with total mean scores of 17.08 (7.8) among the study participants.

* Statistically significant.

in a study in India evaluating patient satisfaction levels at a health facility in North India, reported similar demographic findings with over three quarters of the participants being female [5]. Education profile of patients plays a major role in their assessment of patient care facilities. The Education status of around $70 \%$ of our respondents was Higher Secondary qualification or above. This is much higher than the Education profile reported by Gadalean., et al. (2011) in a study conducted in Romania [6].

In our study, a large majority of patients about $79 \%$ found the seating arrangements in the OPD satisfactory and comfortable and around $81 \%$ of respondents found the waiting area comfortable with adequate ventilation etc. These figures are much higher than most other studies especially from developing countries. The Toilet facilities was the single most important source of dissatisfaction in infrastructure related issues reported by patients in this study. Although a point for concern, our figures are better than many other studies [7]. In a study by Sharma., et al. (2014) over two-thirds of participants had rated the toilet facilities as unsatisfactory [8]. A report by Saini., et al. (2013) echoed similar findings [9]. Another area of concern in the patient satisfaction survey was the availability of clean Drinking Water. Almost around 30\% of the respondents in our study found the availability of drinking water facility in the OPD waiting areas unsatisfactory. The study by Sharma., et al. (2014) noted that more than half of patients were dissatisfied with the water facility in the OPD [8]. Amongst other Interpersonal factors, the prolonged waiting times is a vital predictor of reduced patient satisfaction. Almost $72 \%$ of the respondents in our study found the waiting time taken to be seen by the doctor as too long and were not satisfied on this count. This finding was similar to research conducted by Gajovic., et al. 2012, who found an inverse relationship to that the patients' levels of overall satisfaction with increased waiting times [10]. The majority of respondents in this study expressed overall satisfaction with the facilities and level of care they received at this Hospital. While a number of studies have established that demographic characteristic such as Gender, Age and Education were strongly associated with overall patient satisfaction, our study did not establish any statistically significant association of Age and Gender with Patient Satisfaction [11]. However, this study found that Patients who had basic primary schooling were more satisfied than patients who received higher secondary and tertiary education, establishing a statistically significant ( $p$ $<0.05$ ) inverse relationship between Education Status and Patient Satisfaction on the level of care received at the hospital.

\section{Conclusion}

Every Hospital tries to achieve and maintain very high levels of Patient Satisfaction. In this competitive era, a hospital which strives for patient satisfaction has much to gain. Satisfied patients are more likely to comply with prescribed treatments, return to the facility for future medical needs and recommend the hospital to others. The present study has provided valuable insight regarding patient satisfaction with outpatient health care services, and the predictors thereof. It may be useful in the future to investigate the satisfaction levels of other categories of patients such as inpatients and patients in specific super speciality OPDs, for comparative and sphere based remedial purposes. Furthermore, it would be interesting for other hospitals in similar settings to research patient satisfaction levels, to identify and improve on the impediments to patient satisfaction. 
Assessment of Factors Influencing the Patients' Level of Satisfaction from Health Care Services Provided in the Outpatient Department of a Tertiary Care Hospital: A Cross-Sectional Study

\section{Appendix}

Questionnaire

(Patient Satisfaction towards OPD Services)

Your response will be kept strictly confidential and used only for the purpose of resea exposed to any other purpose. The information provided will help in improving the ser therefore please answer honestly and correctly. You have every right to withdraw fro time

Date of the Interview:

\section{Part-A - Socio Demographic Factors:}

1. What is your name?

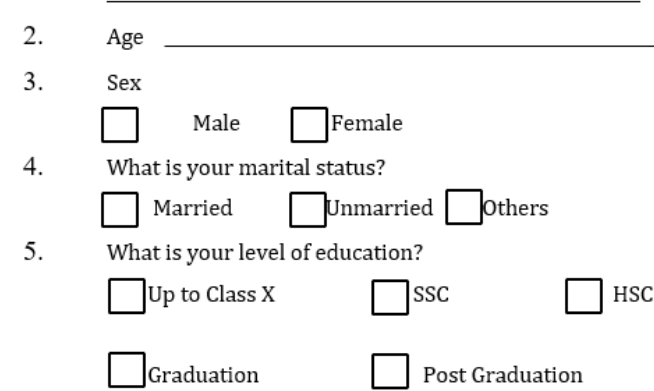

6. What is the total members of your family currently living with you?

7. Total number of visits to hospital during last 12 months?

Part-B - Factors Related to Patient Satisfaction In OPD

Please rate each statement below regarding service quality in the OPD Servides as you perceive. You can rate each statement on a scale of 1 to 5 as below with ' 1 ' means you are 'Completely Satisfied' and ' 5 ' denoting you are 'Completely Dissatisfied' with that statement. The range of scale is as detailed: Completely Satisfied

Some What Satisfied

Neutral

Some What Dissatisfied

Completely Dissatisfied

Infrastructure Related Facilities -

8. Is the seating arrangement and other facilities in the waiting area of the OPD satisfactory?

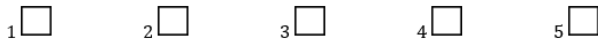

9. Were you satisfied with the general cleanliness of the waiting areas?

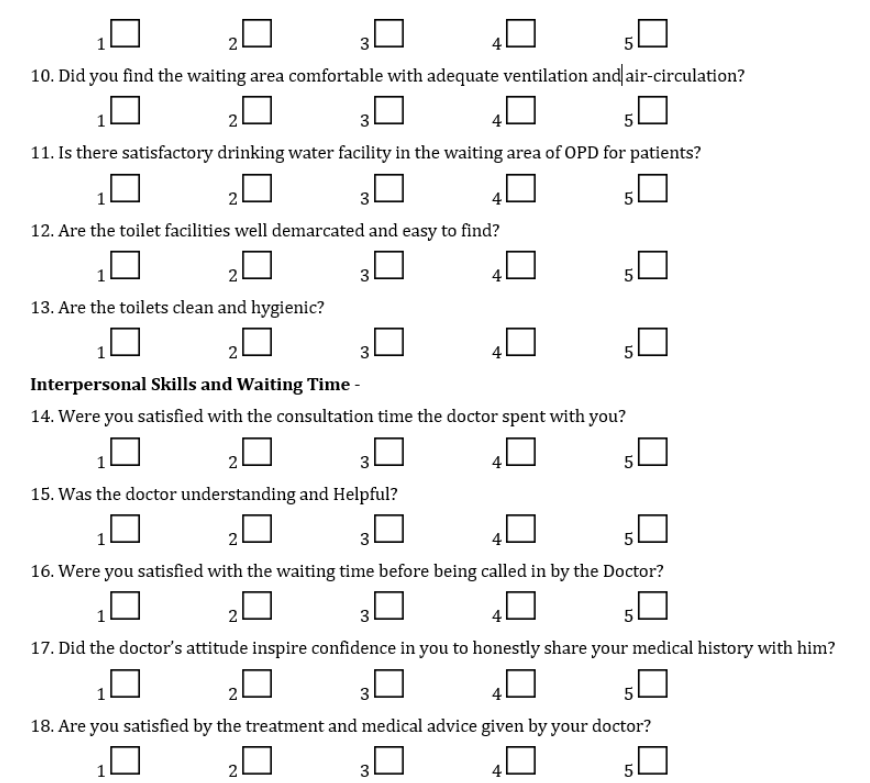

Reception and Registration Services -

19. Were you satisfied with the number and attitude of registration staff in OPD?

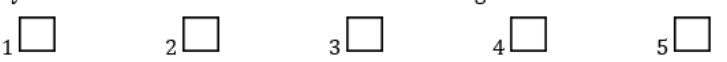

20. Was the registration process smooth, simple and trouble free for you?

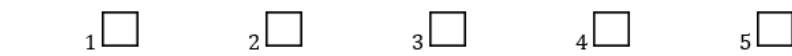

Part-C - Overall Patient Satisfaction towards OPD Services

21. I am happy with the infrastructure, facilities and treatment I received at this Centre.

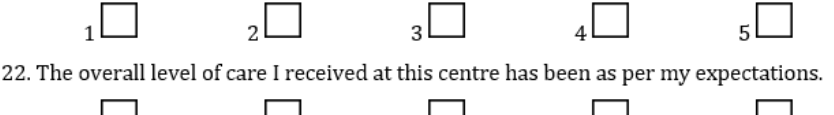

23. If required, I would visit the hospital oPD again and also recommend it to others

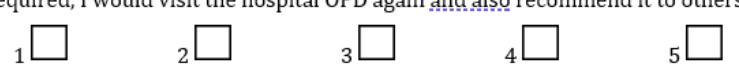

\section{Thank You for Spending Time to Answer}

The present study has provided valuable insight regarding patient satisfaction with outpatient health care services, and the predictors thereof. It may be useful in the future to investigate the satisfaction levels of other categories of patients such as inpatients and patients in specific super speciality OPDs, for comparative and sphere based remedial purposes. Furthermore, it would be interesting for other hospitals in similar settings to research patient satisfaction levels, to identify and improve on the impediments to patient satisfaction.

\section{Bibliography}

1. Anderson L and Dedrick RF. "Development of the Trust in Physician Scale: A measure to assess interpersonal trust in patient physician relationships". Psychological Reports 67 (1990): 1091-1100.

2. Andaleeb S. "Service quality perceptions and patient satisfaction: A study of hospitals in a developing country". Social Science and Medicine 52 (2001): 1359-1370.

3. Balkrishnan R., et al. "Trust and satisfaction with physicians, insurers and medical profession". Journal of Medical Care 41.9 (2003): 1058-1064.

4. Bennett R and Barkensjo A. "Relationship quality, relationship marketing, and client perceptions of the levels of service quality of charitable organizations (2005).

5. Galhotra A., et al. "A cross sectional study on patient satisfaction toward services received at rural health centre, Chandigarh, North India". Annals of Tropical Medicine and Public Health 6 (2013): 240-244. 
6. Emmanuel Kabengele Mpinga and Phillipe Chastonay. "Patient Satisfaction studies and the monitoring of the right to health: Review literature". Global Journal of Health Science 3.1 (2011).

7. Ester L Verhovsek., et al. "The Perception of inter professional communication and its impact on patient care, occupational stress". The Internet Journal of Radiology 12.2 (2012).

8. Sharma A., et al. "Patient Satisfaction about hospital services: A study from the Outpatient Department of tertiary care hospital, Jabalpur, Madhya Pradesh, India". National Journal of Community Medicine 5 (2014): 199-203.

9. Saini NK., et al. "Comparative assessment of satisfaction among outpatient department patients visiting secondary and tertiary level government hospitals of a district in Delhi". Indian Journal of Community Medicine 38 (2013): 114-117.

10. Gajovic G., et al. "Satisfaction of users in primary health care". Health MED 6 (2012): 4185-4194.

11. Galhotra A., et al. "A cross sectional study on patient satisfaction toward services received at rural health centre, Chandigarh, North India". Annals of Tropical Medicine and Public Health 6 (2013): 240-244.

Volume 5 Issue 11 November 2021

(c) All rights are reserved by Suman Anand., et al. 